\title{
Seroprevalence of onchocerciasis in Ogun State, Nigeria after ten years of mass drug administration with ivermectin ${ }^{\ddagger}$
}

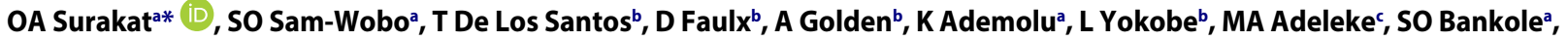 \\ ON Adekunled, WA Abimbola ${ }^{d}$ and CF Mafiana ${ }^{e}$
}

aDepartment of Pure and Applied Zoology, College of Biosciences, Federal University of Agriculture, Abeokuta, Nigeria

'Programme for Appropriate Technology in Health (PATH), Seattle, WA, USA

'Department of Biological Sciences, Osun State University, Osogbo, Nigeria

${ }^{d}$ Department of Plant Science and Applied Zoology, Olabisi Onabanjo University, Ago-Iwoye, Nigeria

${ }^{e}$ Deputy Executive Secretary's Office, National University Commission, Abuja, Nigeria

"Part of the work had been presented as a poster at the European and Developing Countries Clinical Trial Partnership (EDCTP) summit in Lusaka, Zambia between 5-9 November, 2016.

*Corresponding author, email: banjisurakat@gmail.com

Background: This serological study conducted between March and July 2015 investigated the status of onchocerciasis in Ogun State, Nigeria after a decade of mass drug administration (MDA) with ivermectin. Baseline information from the rapid epidemiological mapping of onchocerciasis (REMO) prior to MDA had indicated that Ogun State was meso-endemic to onchocerciasis. Following years of treatment with ivermectin, it has become important to investigate the current status of the disease using more sensitive diagnostic methods.

Methods: The study was conducted in 32 communities in eight onchocerciasis-endemic local government areas (LGAs). Using the Ov16 rapid diagnostic test (Ov16 RDT), finger-prick whole blood was obtained from 3895 consented participants from age five and above. Skin snips were obtained from a subset of 481 corresponding participants as the majority of community members did not consent to skin snipping.

Results: Study revealed a cumulative seroprevalence of $9.3 \%(\mathrm{Cl} 9.29-9.31 \%)$ by RDT and $17.3 \%$ (Cl 16.73-18.34\%) microfilaridermia prevalence by the skin snip subset. Seroprevalence among children between the ages of five and nine was 2.9\% (CI 1.74-3.53\%) across all LGAs. A community microfilaria load (CMFL) between 0 and $1.21 \mathrm{MF} /$ skin snip was recorded in the different communities studied. Among the studied LGAs, children in Odeda LGA recorded the highest seroprevalence by RDT (14.9\%) followed by Abeokuta North (5.1\%), Abeokuta South (4.8\%) and Imeko-Afon (0.6\%), while Ewekoro, Ifo, Obafemi-Owode and Yewa North LGAs recorded zero prevalence.

Conclusion: It appears that the elimination of onchocerciasis in some LGAs is possible considering the lack of new infection among children and the hypo-endemicity among the adult population. However, the microfilaria prevalence observed among adults is of concern as it may imply that mass treatment has not been effective. Increased therapeutic coverage is advised to fully maximise the potential of ivermectin treatment to achieve the disease elimination.

Keywords: CMFL, ivermectin, Nigeria, Onchocerciasis, Ov16 RDT, Ogun State, seroprevalence

\section{Background}

Onchocerciasis is an irreversible blinding disease associated with infection with the parasite Onchocerca volvulus, which is transmitted by insect vectors of the Simulium species. It is distributed mostly along communities with fast-flowing rivers with rocky vegetation, which serves as suitable breeding ecology for the vectors. ${ }^{1-3}$ The disease is of global concern as it is found in 31 African countries, Yemen and South America with confirmed elimination in Mexico, Ecuador, Guatemala and Colombia. ${ }^{4-8}$ Nigeria ranks among those countries with the highest burden of the disease in the world, accounting for about a third of the global prevalence. ${ }^{9-12}$

Control of onchocerciasis is anchored on annual mass drug administration (MDA) of ivermectin (Mectizan ${ }^{\oplus}$, donated by Merck \& Co., Inc., NJ, USA) a freely distributed potent microfilaricide which kills the $O$. volvulus microfilaria in the human host and reduces greatly the disease burden. In the past, computer-based models had projected 25 years' long-term continuous treatment with ivermectin to achieve the suppression and interruption of $O$. volvulus transmission. ${ }^{13}$ While this model is exhaustive, factors such as baseline infection rate, endemicity (intensity of transmission) and numerous programmatic issues e.g. (85\% therapeutic coverage and adherence) have suggested that 5-15 years of mass treatment with ivermectin could interrupt transmission. ${ }^{4-15}$ As a result of long-term treatment with ivermectin, elimination of onchocerciasis in certain foci in Africa now appears to be possible. ${ }^{16-18}$ Successes recorded in MDA and increased global efforts to eliminate onchocerciasis and other neglected tropical diseases (NTDs) as a public health concern by the World Health Organization has called for a need for fielddeployable sensitive diagnosis and disease surveillance tools. ${ }^{19,20}$

Skin biopsy is the standard diagnosis of onchocerciasis and it involves detection of microfilaria in the subcutaneous area of the upper iliac crest of an individual. ${ }^{13}$ However, the inability to sufficiently detect early infections in persons with low microfilaria density and the associated invasive procedure are among the numerous challenges encountered in the quantification of onchocerciasis prevalence in endemic areas. ${ }^{18}$ Sensitive diagnostic tools to evaluate treatment progress in regions with low prevalence, continuous MDA and where control intervention has stopped are important in decision-making in any control programme. In recent times, Programme for Appropriate 
Technology in Health (PATH) and Standard Diagnostics (Yonginsi, Gyeonggi-do, South Korea) made commercially available point-of-care RDT, which detects antibodies to a parasite antigen called Ov 16 by checking for these antibodies in a single drop of blood from a finger prick. ${ }^{21}$

Ogun State, located in Southwest Nigeria, has eight local government areas (LGAs) in which onchocerciasis is endemic. Some of the communities in this LGAs are traversed by the Ogun and Osun River systems, which have rocky substratum and vegetation suitable for breeding of vector species. ${ }^{22,23}$ Control efforts using community-directed treatment with ivermectin (CDTI) have been ongoing since 2004 following rapid epidemiological mapping of onchocerciasis (REMO), which provided a cumulative nodule prevalence of $22.7 \% .^{24}$ Sam-Wobo et al. ${ }^{16}$ conducted epidemiological studies in a few sentinel communities along the Ogun River to measure the impact of mass treatment and microfilaria status in the human population and reported the first evidence of the possibility of onchocerciasis elimination in Ogun State.

To further determine the impact of MDA and the possibility of elimination of onchocerciasis in endemic LGAs of Ogun State, epidemiological studies using the Ov-16 RDT and skin snip microscopy was conducted in 32 onchocerciasis endemic communities in Ogun State, Nigeria.

\section{Materials and methods}

\section{Study location and design}

The study was conducted between March and July 2015. Using a grid sampling method, 32 first-line onchocerciasis-endemic communities from eight LGAs in Ogun State were selected for the study seven months after the last round of ivermectin mass treatment. The LGAs included Abeokuta North, Abeokuta South, Ewekoro, Ifo, Imeko Afon, Obafemi Owode, Odeda and Yewa North (Figure 1). The study communities fall within the derived savannah and forest bio-climatic belt of the state. Data obtained from the State Ministry of Health revealed an annual therapeutic coverage between $65 \%$ and $85 \%$ employing the CDTi strategy. A GPS device was employed to take the coordinates of each of the community sampled for geo-referencing.

\section{Study population}

Communities with a population of not more than 300 were selected for ease of assessment and logistic coordination. Information on the community population was obtained from treatment records detailed in the annual ivermectin distribution by community directed distributors (CDDs). With the aid of photographs and posters, community members were addressed on the importance of the study using the Yoruba, Hausa or French language as some communities were host to immigrants from the neighbouring French-speaking Benin Republic.

\section{Ethical clearance and permission}

Ethical approval for the study was obtained from the Ethics Review Committee (ERC) of Ogun State Hospital Management Board, Abeokuta (trial registration number: SHA/RES/VOL.2/153). Informed consent forms were duly signed by voluntary participants and by parents or guardians of child participants during the skin snip and Ov16 RDT study. Consent to participate in either skin snips, finger prick or both was contained in a questionnaire administered to each participant prior to the study. Participants were allowed to freely decide their preference without coercion.

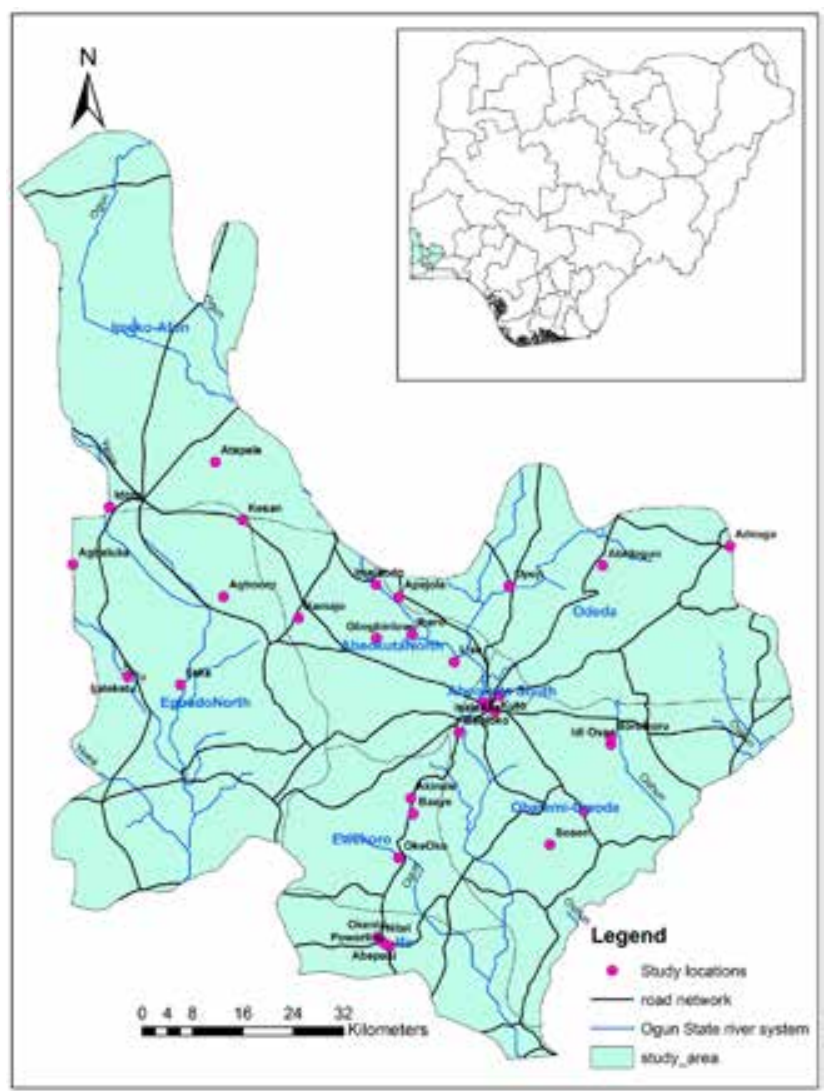

Figure 1: Map showing the study locations and LGAs in Ogun State.

\section{Inclusion criteria}

Males and females aged five years of age and above of all ethnic groups residing in first-line communities were included for the serological and parasitological assessment according to standard protocols.

\section{Rapid diagnostic test (RDT)}

Participants were serially arranged in a census form and the corresponding number was written on each Alere ${ }^{\mathrm{TM}}$ SD Bioline IgG4 test kit (Abbott Laboratories, Abbott Park, IL, USA) cassette using a permanent marker for easy identification. The kit was used according to the manufacturer's instruction. In sum, the alcohol swab included in the pack was opened and used to clean the finger to be pricked using a circular motion for $10 \mathrm{~s}$; the swabbed finger was allowed to air dry. The participant's finger was pricked with a lancet to obtain a drop of blood and the lancet was discarded into the biohazard-labelled sharps container. The first drop of blood was used for the RDT. Using the capillary pipette provided in the test kit, $10 \mu \mathrm{l}$ of blood was collected to fill up to the marked line on the pipette. A clean piece of gauze was used to apply pressure on the pricked finger to stop bleeding following blood collection.

The $10 \mu \mathrm{L}$ collected blood was added to the round sample well on the test kit cassettes and absorbed by the sample pad of the test. The capillary pipette was also discarded in the sharps container. Four drops of assay diluent were then added into the square buffer well on the test kit cassette and the timer was started. After $30 \mathrm{~min}$ the result was read. The area marked ' $C$ ' on the test cassette stands for the control line, while the area marked ' $T$ ' designates the test line. Valid results include areas on the result window on the cassette showing either two lines of the 
control ' $C$ ' and test ' $T$ ' implying 'positive', or the area marked control ' $C$ ' alone implying 'negative'. Invalid results include result window panel with ' $T$ ' line alone appearing without ' $C$ '.

\section{Skin snip examination}

Two bloodless skin biopsies of each participant were obtained from the left and right posterior iliac crest with the aid of a $2 \mathrm{~mm}$ corneoscleral punch (Holth and Modified Walser) and placed on a glass slide with a drop of saline water. The tissues in the slides were examined under a $\times 40$ binocular microscope after $30 \mathrm{~min}$

Table 1: Seroprevalence of onchocerciasis in selected communities

\begin{tabular}{|c|c|c|c|c|c|}
\hline Local government area & Community & $\begin{array}{l}\text { Number examined by Ov } \\
16 \text { RDT }\end{array}$ & No. (+)ve (\%) & $\begin{array}{c}\text { Number of children (5-9) } \\
\text { years examined }\end{array}$ & $\begin{array}{l}\text { Prevalence in children } \\
\text { aged 5-9 years (\%) }\end{array}$ \\
\hline \multirow[t]{4}{*}{ Abeokuta North } & Gbegbinlawo & 80 & $15(19)$ & 21 & $(0)$ \\
\hline & Ibaro & 125 & $43(34)$ & 19 & $1(5.3)$ \\
\hline & Imala odo & 199 & $10(6)$ & 36 & $2(5.6)$ \\
\hline & Lisa & 36 & $14(39)$ & 3 & $1(33.3)$ \\
\hline Sub-total & & 440 & $82(19)$ & 79 & $4(5.1)$ \\
\hline \multirow[t]{4}{*}{ Abeokuta South } & Isale Ake & 123 & $8(7)$ & 20 & $2(10)$ \\
\hline & Itori Odo & 116 & $7(6)$ & 13 & 0 \\
\hline & Kuto & 239 & $1(0.4)$ & 19 & 0 \\
\hline & Oke Iganna & 109 & $5(5)$ & 11 & $1(9.1)$ \\
\hline Sub-total & & 587 & $21(4)$ & 63 & $3(4.8)$ \\
\hline \multirow[t]{4}{*}{ Ewekoro } & Akinale & 147 & $12(8)$ & 22 & 0 \\
\hline & Baaye & 78 & 0 & 29 & 0 \\
\hline & Banjoko & 239 & $7(3)$ & 57 & 0 \\
\hline & Oke Oko & 37 & 0 & 5 & 0 \\
\hline Sub-total & & 501 & $19(4)$ & 113 & 0 \\
\hline \multirow[t]{4}{*}{ Ifo } & Abepaki & 98 & 0 & 15 & 0 \\
\hline & Anuoluwapo & 134 & $1(0.7)$ & 23 & 0 \\
\hline & Nitel/powerline & 144 & 0 & 24 & 0 \\
\hline & Oke nla & 123 & $1(0.8)$ & 18 & 0 \\
\hline Sub-total & & 499 & $2(0.4)$ & 80 & 0 \\
\hline \multirow[t]{4}{*}{ Imeko Afon } & Agbaluka & 133 & $5(3.7)$ & 73 & 0 \\
\hline & Atapele & 107 & $24(22.4)$ & 27 & 0 \\
\hline & Idofa & 230 & $14(6.1)$ & 45 & 0 \\
\hline & Kesan & 164 & $23(14)$ & 36 & $1(2.8)$ \\
\hline Sub-total & & 634 & $66(10.4)$ & 181 & $1(0.6)$ \\
\hline \multirow[t]{4}{*}{ Obafemi Owode } & Boru Boru & 31 & $1(3.2)$ & 3 & 0 \\
\hline & Idi Osan & 60 & $4(7)$ & 10 & 0 \\
\hline & Ogbe Eruku & 95 & $17(18)$ & 10 & 0 \\
\hline & Soseri & 147 & $13(9)$ & 24 & 0 \\
\hline Sub-total & & 333 & 35 (10.5) & 47 & 0 \\
\hline \multirow[t]{4}{*}{ Odeda } & Abidogun & 136 & $51(38)$ & 28 & $4(14.3)$ \\
\hline & Adeaga & 76 & $9(12)$ & 14 & (0) \\
\hline & Apejola & 75 & $4(5.3)$ & 21 & (0) \\
\hline & Opeji & 155 & $74(48)$ & 25 & $9(36)$ \\
\hline Sub-total & & 442 & $138(31.2)$ & 88 & $13(14.8)$ \\
\hline \multirow[t]{4}{*}{ Yewa North } & Agbooro & 65 & 0 & 8 & 0 \\
\hline & Bamajo & 38 & $1(2.6)$ & 6 & 0 \\
\hline & Ijaka Isale & 181 & 0 & 27 & 0 \\
\hline & ljale ketu & 175 & 0 & 27 & 0 \\
\hline Sub-total & & 459 & $1(0.2)$ & 68 & 0 \\
\hline Grand total & & 3895 & 364 (9.3) & 719 & $21(2.9)$ \\
\hline
\end{tabular}

for micro-filarial manifestation. After examination, each skin tissue was incubated in a 96-well microtitration plate containing a normal saline solution and when the column was full the wells were covered with a transparent adhesive film and kept for reexamination within $24 \mathrm{~h}$. After $24 \mathrm{~h}$, the biopsies were removed with curved tweezers and the fluid from each well was examined separately on a slide for microfilaria. After each skin snip in the field, the scleral punch was thoroughly sterilised in hot water for $10 \mathrm{~min}$ followed by sequential washing with sodium hypochlorite solution, distilled water and alcohol before re-used. ${ }^{16}$ Microfilaria 
results were expressed as positive ( $\mathrm{mf}$ present) or negative ( $\mathrm{mf}$ absent); mf prevalence was expressed as number of persons positive divided by the total number of persons examined. ${ }^{16}$

\section{Data analysis}

The community microfilarial load (CMFL) was defined as the geometric mean number of microfilariae per skin snip ( $\mathrm{mf} / \mathrm{ss})$ among adults aged 20 years or more. It was calculated using a $\log (x+1)$ transformation CMFL $=\left(e^{\frac{1}{N} \sum \ln (x+1)}-1\right)$ where $x$ is the individual microfilarial density, and $\mathrm{N}$ the total number of individuals aged 20 years and above. Individual data were entered and coded in Windows 8.1 Microsoft Excel $^{\oplus}$ (Microsoft Corp, Redmond, WA, USA) and analysed statistically using SPSS ${ }^{\odot}$ version 20 (IBM Corp, Armonk, NY, USA). Frequencies and percentages were used to group variables while variation and association in (sero)prevalence were analysed using Pearson's chi-square test.

\section{Results}

\section{Demographic information of study participants}

A total of 3895 participants with age ranging from 5 to 98 years enrolled for the Ov16 RDT study. A subset $(n=481)$ of study participants consented to provide skin snips for microscopic examination of microfilaria (MF) emergence. Analysis of demographic data showed that $58 \%$ were females and $42 \%$ were males. The ages of study participants were grouped into the following class intervals: 5-9, 10-14, 15-19, 20-29, 30-49 and $\geq 50$ respectively with each representing 719 (18.5\%), 693 (17.8\%), 254 (6.5\%), 483 (12.4\%), 959 (24.6\%) and 787 (20.2\%).

\section{Cumulative seroprevalence of onchocerciasis by $R D T$ in each community and $L G A$}

An overall seroprevalence of onchocerciasis recorded for the eight endemic LGAs studied by RDT was 9.3\% (CI 9.29-9.31\%) (Table 1). There were variations in the distribution of seroprevalence by Ov16 RDT across the different communities studied. Communities in Odeda LGA reported the highest $O$. volvulus exposure (31.2\%) while communities in Yewa North LGA recorded the lowest $(0.2 \%)$ (Figure 2 ). Seroprevalence of onchocerciasis was not statistically significant among the different LGAs studied (chi-square $=2.301, \mathrm{df}=1$ and $p=0.129$ ).

\section{Age, and Gender Seroprevalence by RDT}

There was a significant relationship between age and seroprevalence (chi-square $=86.589, \mathrm{df}=3, p=0.000$ ) (Figure 3 ).

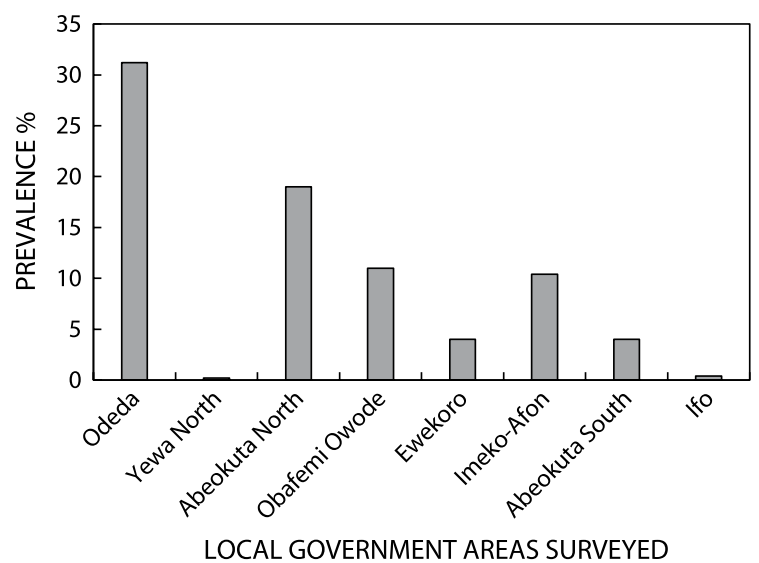

Figure 2: Seroprevalence of Onchocerca volvulus across the different LGAs.

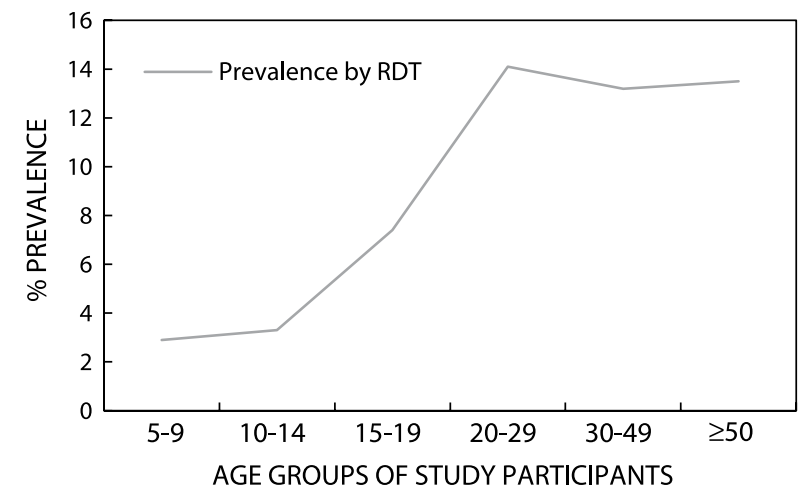

Figure 3: Cumulative seroprevalence by age across all LGAs.

Although seroprevalence varied among different age groups in all the LGAs, the highest prevalence of $14.1 \%$ (Cl 12.9\%-15.6\%) was recorded among participants in the age group 20-29 years and the lowest at $2.9 \%$ among age class 5-9 (Cl 1.74-3.53\%). Conversely, there was no significant relationship (chisquare $=2.301, \mathrm{df}=1, p=0.129$ ) between prevalence and gender. Of the 1646 males 170 were seropositive, representing 10.3\%, and of 2249 females 194, representing 8.6\%. Among children between the ages of 5 and 9 years who are markers to indicate ongoing transmission, children in Yewa North, Obafemi-Owode, Ewekoro and Ifo LGA recorded a zero prevalence compared with Odeda (14.8\%), Abeokuta North (5.1\%), Abeokuta South (4.8) and Imeko-Afon (0.6\%).

\section{Microfilaria prevalence across age groups in all LGAs}

The study revealed no significant relationship between age and prevalence by skin snip (chi-square $=3.835$, $\mathrm{df}=1, p=0.0502$ ) Overall MF prevalence was $17.3 \%$ (Cl 16.73-18.34\%) (Table 2). All communities were surveyed with the exception of communities in Ifo and Abeokuta South LGA whose members did not consent to be skin snipped. CMFL was less than one MF per skin snip in all communities sampled with the exception of Idofa in Imeko Afon LGA who recorded 1.21 MF per skin snip. Prevalence by age showed that participants within the age group 5-9 years recorded the least infection (4.8\%) while those in the age class $15-19$ years recorded the highest (28.4\%) (Table 3 ).

\section{Discussion}

Onchocerciasis seroprevalence ranging between $0 \%$ and $31.2 \%$ was observed in the different LGAs indicating that individuals in communities may be reservoirs of past infections. This would have been corroborated by the comparative corresponding microfilaria study but, regrettably, $88 \%$ of the study population refused to be skin snipped owing to past experience of the painful and invasive nature of this method, which reinforced their unwillingness to cooperate. Despite this limitation, a cumulative seroprevalence of 9.3\% (Cl 9.29-9.31\%) was observed across all age groups and a $2.9 \%$ (Cl 1.74-3.53\%) seroprevalence among children $<10$ years of age in all LGAs.

Our findings among children have severe epidemiological implications since they are considered 'serological markers' of recent transmission of $O$. volvulus. ${ }^{25}$ this is likely to indicate that MDA has not been that effective in affected LGAs. The serological exposure observed among the adult population ought to have been of little consequence in the elimination of onchocerciasis as it may imply that they had been infected prior to initiation of MDA activities and therefore could still be having a historic sero- 
Table 2: Community microfilaria load of Onchocerca volvulus in the study communities

\begin{tabular}{|c|c|c|c|c|c|}
\hline Local government area & Community & Number examined & Number infected & Prevalence & CMFL \\
\hline \multirow[t]{4}{*}{ Abeokuta North } & Gbegbinlawo & 23 & 3 & 13 & 0.2 \\
\hline & Ibaro & 34 & 4 & 11.7 & 0.3 \\
\hline & Imala odo & 19 & 4 & 21.1 & 0.4 \\
\hline & Lisa & 15 & 3 & 20 & 0.2 \\
\hline \multirow[t]{4}{*}{ Ewekoro } & Akinale & 17 & 0 & 0 & 0 \\
\hline & Baaye & 12 & 0 & 0 & 0 \\
\hline & Banjoko & 20 & 0 & 0 & 0 \\
\hline & Oke Oko & 22 & 0 & 0 & 0 \\
\hline \multirow[t]{3}{*}{ Imeko Afon } & Agbaluka & 30 & 1 & 3.3 & 0.2 \\
\hline & Atapele & 14 & 3 & 21.4 & 0.3 \\
\hline & Idofa & 19 & 7 & 36.8 & 1.2 \\
\hline \multirow[t]{4}{*}{ Obafemi Owode } & Boru Boru & 14 & 3 & 21.4 & 0.5 \\
\hline & Idi Osan & 17 & 0 & 0 & 0 \\
\hline & Ogbe Eruku & 21 & 4 & 19.1 & 0.7 \\
\hline & Soseri & 15 & 5 & 26.7 & 0.6 \\
\hline \multirow[t]{4}{*}{ Odeda } & Abidogun & 11 & 4 & 36.4 & 0.4 \\
\hline & Adeaga & 23 & 6 & 26.1 & 0.3 \\
\hline & Apejola & 7 & 2 & 28.6 & 0.9 \\
\hline & Opeji & 57 & 17 & 29.8 & 0.4 \\
\hline \multirow[t]{3}{*}{ Yewa North } & Agbooro & 16 & 2 & 12.5 & 0.3 \\
\hline & Bamajo & 17 & 4 & 23.5 & 0.7 \\
\hline & ljaka Isale & 18 & 3 & 16.7 & 0.8 \\
\hline
\end{tabular}

Table 3: Overall age microfilarial prevalence of Onchocerca volvulus in the study communities

\begin{tabular}{|l|c|c|}
\hline Age groups (years) & Number examined & Number infected \\
\hline $5-9$ & 84 & $4(4.8)$ \\
\hline $10-14$ & 69 & $7(10.1)$ \\
\hline $15-19$ & 67 & $19(28.4)$ \\
\hline $20-29$ & 86 & $13(15.1)$ \\
\hline $30-49$ & 83 & $10(12.1)$ \\
\hline$\geq 50$ & 92 & $30(12)$ \\
\hline Total & 481 & $83(17.3)$ \\
\hline
\end{tabular}

response to the Ov16 antigen. ${ }^{26,27}$ This does not appear to be the case as the study outcome among the child population implies that they were recently exposed to the disease. Similarly, the high MF intensities and prevalence estimates among adults after seven months of prior treatment is suggestive that transmission is ongoing in affected LGAs.

Following a 10-year period of MDA with ivermectin, infection or exposure among children under recurrent treatment is expected to be $<0.1 \% .^{26,28}$ This was the case in four LGAs with the exception of communities in Odeda, Imeko Afon, Abeokuta North and South LGAs, which calls for attention. On the other hand, the zero exposure in Yewa North, Obafemi-Owode, Ewekoro and Ifo LGAs should be a good measurement of the MDA activities in Ogun State. This ought hypothetically to indicate interruption of MF densities in the adult population and a break in transmission of new infection to children below the age of five or individuals who recently crossed the age five threshold being considered safe for the uptake of ivermectin. ${ }^{29}$ Unfortunately, the data show that MF densities in adults have not been eliminated in many LGAs and therefore transmission is still possible.

Interestingly, the CMFL observed in the study appeared to be very low owing to the intensity of infection, since the aim of controlling onchocerciasis with ivermectin is focused on reducing the vectorial potential of the Simulium vectors to pick up microfilariae during a blood meal for onward transmission. The overall CMFL of $<5 \mathrm{mf} / \mathrm{skin}$ snip observed may potentially reduce the risk of new infection, although some mathematical modelling has shown that under certain circumstances transmission can persist at very low parasite densities..$^{30}$ The declining community participation in this skin snip was a limitation to reaching a definite conclusion.

Importantly, the exposure to $O$. volvulus and MF prevalence observed among adults and children in Odeda LGA, a semiurban settlement, is worrisome. The variation in this pattern of seroprevalence compared with other LGAs could be attributed to the proximity of communities in Odeda LGA to the Ogun River, a major focus in the state's onchocerciasis control programme. The river is a potent breeding site responsible for consistent bites by the $S$. damnosum sl vectors. Studies have shown that communities along these river systems are at higher risk owing to the preponderance of the Simulium vectors in these areas. ${ }^{23}$ 
Considering the 10 years of MDA in the state, the increase in prevalence and past exposure with the corresponding increase in age observed in the study is an epidemiological flashpoint that should be taken seriously. The disease persistence in Ogun State despite the treatment history may be attributed to the reservoirs of a high level of transmission before MDA implementation, rural-urban human migration due to the state's proximity to the neighbouring Benin Republic and four adjoining states, poor geographic and therapeutic treatment coverage, and difficult in reaching endemic areas during MDA implementation. ${ }^{3,31,32}$

\section{Conclusion}

The serological data obtained in this study serve as baseline information for future studies and epidemiological planning in Ogun State. It appears that the elimination of onchocerciasis in Yewa North, Obafemi-Owode, Ewekoro and Ifo LGAs is possible considering the serological information, which has shown the lack of new infection among children. This is also supported by the value of CMFL observed, which is also in agreement with similar studies on CMFL by Sam-Wobo et al. ${ }^{16}$ This seeming success may be short-lived if appropriate measures are not put in place for increased therapeutic coverage.

\section{List of abbreviations}

$\begin{array}{ll}\text { CDA } & \text { Community development association } \\ \text { CDTI } & \begin{array}{l}\text { Community directed treatment with } \\ \text { ivermectin }\end{array} \\ \text { CMFL } & \text { Community microfilaria load } \\ \text { ERC } & \text { Ethics Review Committee } \\ \text { GPS } & \text { Geographical positioning system } \\ \text { IgG4 } & \text { Immunoglobulin 4 } \\ \text { MDA } & \text { Mass drug administration } \\ \text { MF } & \text { Microfilaria } \\ \text { PATH } & \begin{array}{l}\text { Programme for Appropriate Technology in } \\ \text { Health }\end{array} \\ \text { RDT } & \text { Rapid diagnostic test } \\ \text { REMO } & \text { Rapid epidemiological mapping of } \\ & \text { onchocerciasis } \\ \text { WHO } & \text { World Health Organization }\end{array}$

Funding - No funding was received for field activities during the study; however, the Ov16 RDT was provided as commodity support by PATH, Seattle, WA, USA.

Disclosure statement - No potential conflict of interest was reported by the authors.

\section{ORCID}

OA Surakat iD http://orcid.org/0000-0002-2382-3857

\section{References}

1. Opoku AA. Some observations on the ecology, biting activity and parasite infectivity of the blackfly (Simuliidae) and onchocerciasis prevalence in the River Birim catchment. Ghana J of Sci. 2000;40: 65-73.

2. Adeleke MA, Mafiana CF, Sam-Wobo SO, et al. Morphotaxonomic studies on Simulium damnosum Theobald complex (Diptera: Simuliidae) along Osun River Southwest Nigeria. Acta Entomol Sin. 2010;53(11):1319-24.
3. Hopkins A, Boakye AB. Water and Sanitation Related Diseases and Environment: Challenges, interventions, and Preventive measures. New York City: Wiley-Blackwell. Published by John Wiley and Sons, Inc.; 2011.

4. Cupp EW, Sauerbrey M, Richards F. Elimination of human onchocerciasis: a history of progress and current feasibility using ivermectin (Mectizan $^{\circledR}$ ) monotherapy. Acta Trop. 2010;120(Suppl 1): S100-08.

5. WHO. Sustaining the drive to overcome the global impact of neglected tropical diseases. Second WHO report on neglected tropical diseases. WHO/HTM/NTD/2013.1. Geneva: WHO; 2013 [cited 2016 Sep 12]. Available from: http://www.who.int/iris/ bitstream/10665/77950/1/9789241564540_eng.pdf.

6. WHO. Neglected tropical diseases, WHO declares Ecuador free of onchocerciasis (riverblindness); 2014 [cited 2015 Jun 12]. Available from: http://www.who.int/neglected_diseases/ecuador_free_from_ onchocerciasis/en/.

7. WHO: Progress toward eliminating onchocerciasis in the WHO Region of the Americas: verification of elimination of transmission in Mexico. Wkly Epidemiol Rec. 2015, 90(43):577-81.

8. WHO: Progress towards eliminating onchocerciasis in the WHO Region of the Americas: verification of elimination of transmission in Guatemala. Wkly Epidemiol Rec. 2016, 91(43):501-5.

9. Mafuyai HB, Post RJ, Molyneux $\mathrm{DH}$, et al. First sibling species identifications of Nigerian onchocerciasis vectors. Trans Royal Soc Trop Med Hyg. 1997;91:90-1. https://doi.org/10.1016/S00359203(97)90409-0

10. Noma M, Nwoke BEB, Nutall I, et al. Rapid epidemiological mapping of onchocerciasis (REMO): its application by the African Programme for Onchocerciasis Control (APOC). Ann Tropical Med Parasitol 2002;96(su p1):S29-39. https://doi.org/10.1179/000349802125000637

11. Oyibo WA, Fagbenro-Beyioku AF. Effect of repeated community based ivermectin treatment on the intensity of Onchocerciasis in Nigeria. Rur Rem Health J. 2004;3:211-21.

12. Opara KN, Usip LP, Akpabio EE. Transmission dynamics of Onchocerciasis in rural communities of Akwa Ibom State, Nigeria. J Vec Borne Dis. 2008;45:225-30.

13. Plaisier AP, Alley ES, van Oortmarssen GJ, et al. Required duration of combined annual ivermectin treatment and vector control in the Onchocerciasis Control Programme in west Africa. Bull World Health Org. 1997;75:237-45.

14. Winnen M, Plaisier AP, Alley ES, et al. Can ivermectin mass treatments eliminate onchocerciasis in Africa? Bull World Health Org. 2002;80: 384-91.

15. Evans DS, Alphonsus K, Umaru J, et al. Status of onchocerciasis transmission after more than a decade of mass drug administration for onchocerciasis and lymphatic Filariasis elimination in Central Nigeria: challenges in coordinating the stop MDA decision. PLoS Negl Trop Dis 2014;8(9):e3113. doi:10.1371/journal.pntd.0003113.

16. Sam-Wobo SO, Adeleke MA, Jaiyeola OA, et al. Epidemiological evaluation of onchocerciasis along Ogun River System, South-west Nigeria. J Vec Borne Dis. 2012;49:101-4.

17. Tekle AH, Elhassan $E$, Isiyaku S, et al. Impact of long-term treatment of onchocerciasis with ivermectin in Kaduna State, Nigeria: first evidence of the potential for elimination in the operational area of the African Programme for Onchocerciasis Control. Parasites Vec. 2012;5:28. https://doi.org/10.1186/1756-3305-5-28

18. Carter Center River Blindness (Onchocerciasis) Program. [cited 2015 Sep 11]. Available from: http://www.cartercenter.org/health/river blindness/index.html.

19. WHO. Accelerating work to overcome the global impact of neglected tropical disease. A Roadmap for implementation. World Health Organization, 20 Avenue Appia,Geneva,Switzerland.2012. vol. 1211.

20. Uniting to Combat NTDs. London Declaration on neglected tropical diseases. 2012. [cited 2015 May 24]. Available from: http://unitingtocombatntds.org/sites/default/files/resource_file/ londondeclaration.

21. Golden A, Faulx D, Kalnoky M, et al. Analysis of age-dependent trends in Ov16 lgG4 seroprevalence to onchocerciasis. Parasites Vec. 2016;9:e371-400. https://doi.org/10.1186/s13071-016-1623-1 
22. Sam-Wobo SO, Surakat OA, Adeleke MA, et al. Ecological and attachment profile of Simulium damnosum s.l larva in breeding sites along Ogun river, Ogun State, Nigeria. Journal of Entomology and Zoology. Studies 2014;2(4):197-200.

23. Surakat OA, Sam-Wobo SO, Ademolu KA, et al. Cytospecies composition of simulium damnosum complex (Diptera: Simuliidae) breeding in Oyan River, Southwestern Nigeria. Afr Entomol. 2016;24(1):24-9. https://doi.org/10.4001/003.024.0024

24. Ogun State Ministry of Health. Ivermectin therapeutic treatment coverage records 2014; Unpublished.

25. Rodriguez-Perez MA, Danis-Lozano $R$, Rodriguez $M H$, et al. Comparison of serological and parasitological assessments of Onchocerca volvulus transmission after 7 years of mass ivermectin treatment in Mexico. Trop Med Int Health 1999;4:98-104. https://doi. org/10.1046/j.1365-3156.1999.00363.x

26. Evans DS, Alphonsus K, Umaru U, et al. Status of onchocerciasis transmission after more than a decade of mass drug administration for onchocerciasis and lymphatic filariasis elimination in central Nigeria: Challenges in coordinating the stop of MDA decision. PLOS Negl Trop Dis. 2014; 89:51-7.

27. Vlaminck J, Fischer PU, Weil GJ. Diagnostic tools for onchocerciasis elimination programs. Trends Parasitol. 2015;31(11):571-82. https://doi.org/10.1016/j.pt.2015.06.007
28. Higazi TB, Zarroug IM, Mohamed HA, et al. Interruption of Onchocerca volvulus Transmission in the Abu Hamed Focus, Sudan. Am J Trop Med Hyg. 2013;89(1):51-7. https://doi.org/10.4269/ajtmh.13-0112

29. Lakwo TL, Garms R, Rubaale T, et al. The disappearance of onchocerciasis from the Itwara focus, western Uganda after elimination of the vector simulium neavei and 19 years of annual ivermectin treatments. Acta Trop 2013;126(3):218-21. https://doi. org/10.1016/j.actatropica.2013.02.016

30. Stolk WA, Walker M, Coffeng LE, et al. Required duration of mass ivermectin treatment for onchocerciasis elimination in Africa: a comparative modelling analysis. Parasites Vec. 2015;8(1):239. https:// doi.org/10.1186/s13071-015-1159-9

31. Turner HC, Walker M, Churcher TS, et al. Reaching the London declaration on neglected tropical diseases goals for onchocerciasis: an economic evaluation of increasing the frequency of ivermectin treatment in Africa. Clin Infect Dis 2014;59(7):923-32. https://doi. org/10.1093/cid/ciu467

32. Vincent JA, Lustigman S, Zhang $S$, et al. A comparison of newer tests for the diagnosis of onchocerciasis. Ann Trop Med Parasitol 2000;94:2538.

Received: 13-08-2017 Accepted: 20-11-2017 